Reprod. Nutr. Dévelop., 1987, 27 (1 B), 285-286.

\title{
Influence d'un sirop de glucose sur la digestibilité de la ration chez les brebis et sur la production laitière de vaches
}

Hanna LEONTOWICZ

Chaire de Physiologie des Animaux, Université Agronomique de Varsovie.

Summary. A glucose syrup was substituted for about $15 \%$ of the dry matter in the diet of sheep and dairy cows. In sheep it caused a significant increase of apparent digestibility of organic matter and changed the pattern of rumen fermentation. In cattle it did not significantly increase milk yield, but seemed to improve digestive utilization of ammonia and metabolic use of glucose.

Le sirop de glucose $(60$ à $70 \%$ de matière sèche (MS) constituée de $98 \%$ d'extractif non azoté) est le résidu de l'hydrolyse acide et enzymatique de la fécule de pomme de terre. Ce produit très riche en glucose et à forte concentration énergétique $(14,5 \mathrm{MJ} \mathrm{ME} / \mathrm{kg} \mathrm{MS}$ d'après l'équation de prédiction de Van Es, 1978) peut-il se substituer à l'aliment concentré normalement utilisé dans les rations pour vaches laitières bien pourvues en matières azotées solubles, et avec quels effets sur les orientations fermentaires dans le rumen, I'utilisation de l'azote, la production et la composition du lait ?

Matériel et méthodes. Les essais ont été effectués sur 6 brebis en bilan digestif réparties en 2 lots, expérimental (E) et témoin (T). Les rations des lots $T$ et $E$ contenaient des pulpes de betteraves deshydratées (416 et $278 \mathrm{~g}$ respectivement de $M S / \mathrm{j})$, du foin de prairie $(390 \mathrm{~g}$ de $\mathrm{MS} / \mathrm{j})$, de l'urée $(10 \mathrm{~g})$ et pour le lot $\mathrm{E}$ le sirop de glucose $(129 \mathrm{~g}$ de $\mathrm{MS} / \mathrm{j})$. La teneur en matières azotées était respectivement de 13,2 et $11,2 \%$ MS. Les produits de la fermentation dans le rumen ont été analysés sur du liquide prélevé par tubage et la synthèse d'azote microbien a été estimée par l'excrétion urinaire d'allantoine (Hornawsky et Müller, 1980).

Les traitements $E$ et $T$ ont également été comparés sur 2 lots de 16 et 17 vaches durant 2 périodes expérimentales de 30 jours (au $3^{\mathrm{e}}$ et $4^{\mathrm{e}}$ mois de la lactation), avec inversion des traitements d'une période à la suivante. Les vaches ont reçu du fourrage vert ad libitum, du foin $(3 \mathrm{~kg} / \mathrm{j})$ et de l'aliment concentré lorsque la production de lait dépassait $12 \mathrm{l}$, à raison de $1 \mathrm{~kg}$ de concentré pour 2 et $3 \mathrm{~kg}$ de lait, respectivement dans les lots $T$ et $E$. Les vaches du lot $E$ ont reçu en plus 2,6 kg MS de sirop de glucose mélangé au fourrage distribué le soir. Les concentrations de glucose, d'insuline et d'urée dans le sang et d'acides gras volatils (AGV) dans le rumen ont été mesurées sur 10 vaches par groupe avant le repas du matin et $2 \mathrm{~h}$ après la distribution des repas du matin et du soir.

Résultats et discussion. Chez les brebis, la substitution du sirop de glucose (lot $\mathrm{E}$ ) aux pulpes de betteraves (lot $\mathrm{T}$ ) a provoqué un accroissement significatif des digestibilités apparentes de la matière sèche et de l'extractif non azoté, ainsi que des concentrations en ammoniaque, acide lactique, et des proportions d'acide butyrique dans le rumen (tabl. 1). Les vaches du lot $E$ ont reçu $17 \mathrm{MJ}$ d'énergie métabolisable de plus et $254 \mathrm{~g}$ de matières azotées de moins que celles du lot $\mathrm{T}$. Leurs productions journalières de lait, de matières grasses et de matières 
azotées n'ont pas été significativement supérieures. Les proportions molaires d'acide butyrique et propionique dans le mélange d'AGV ont été significativement plus élevées dans le rumen des vaches recevant le sirop de glucose (tabl. 1). Avec

TABL. 1. - Effet des traitements témoin (T) et expérimental $(E)$ chez les brebis et les vaches laitières.

\begin{tabular}{|c|c|c|c|c|}
\hline Espèces & Régimes & $\mathrm{T}$ & $E$ & $S$ \\
\hline Brebis & $\begin{array}{l}\text { Digestibilité matière sèche } \\
(\%) \text { extractif non azoté } \\
\text { Rumen }(1) \text { - acide lactique (mmol/L) } \\
\quad \text { - acide propionique }(\% \text { molaire) } \\
\text { - acide butyrique ( } \% \text { molaire) } \\
\text { Allantoine dans l'urine }(\mathrm{g} / \text { jour })\end{array}$ & $\begin{array}{c}76,0 \\
83,6 \\
1,3 \\
19,1 \\
10,3 \\
0,42\end{array}$ & $\begin{array}{c}81,4 \\
88,6 \\
2,0 \\
16,1 \\
13,6 \\
0,44\end{array}$ & $\begin{array}{l}x x \\
x x \\
x x \\
x \\
x x \\
N S \\
N\end{array}$ \\
\hline $\begin{array}{l}\text { Vaches } \\
\text { laitières }\end{array}$ & 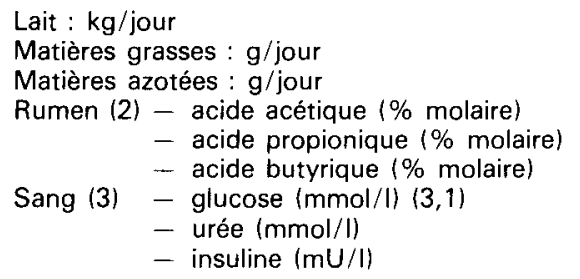 & $\begin{array}{l}20,4 \\
801 \\
613 \\
74,8 \\
14,7 \\
8,3 \\
1,2 \\
9,5 \\
5,2\end{array}$ & $\begin{array}{l}21,2 \\
823 \\
656 \\
71,2 \\
15,7 \\
10,7 \\
0,8 \\
6,7 \\
4,8\end{array}$ & $\begin{array}{l}N S \\
N S \\
N S \\
X X \\
X X \\
X X \\
X X \\
X X \\
\text { NS }\end{array}$ \\
\hline
\end{tabular}

(1) Moyenne des prélèvements $0,1,2$ et $4 \mathrm{~h}$ après le début du repas ; (2) (3) Moyennes des prélèvements 0 et $2 \mathrm{~h}$ après le début du repas et 3-1 $(2 \mathrm{~h}$ après seulement). $\mathrm{S}$ : seuil de signification : $P<0,01(X X)$ et $P<0,05(X)$.

cette ration d'herbe probablement riche en azote soluble, I'utilisation de l'ammoniaque dans le rumen et l'utilisation métabolique du glucose semblent avoir été améliorées par le sirop de glucose. C'est ce que semblent indiquer les concentrations de glucose et d'urée dans le sang significativement plus faibles (deux heures après le repas), pour une concentration presque semblable d'insuline. On peut penser que le concentré de glucose pourrait être une source d'énergie particulièrement intéressante pour des vaches à haut niveau de production, en début de lactation.

Hornawsky G., Müller H., 1980. Arch. exp. vet. Med., 34, 333-337.

Van es A. J. H., 1978. J. anim. Sci., 49, 1431-1437. 